\title{
Mapeamento ambiental como ferramenta de localizaçáo de riscos à saúde
}

Environmental mapping as a health risk location tool

\section{RESUMO}

Este texto apresenta o relato de experiência sobre o mapeamento ambiental em saúde vinculado ao projeto de extensão "Interface entre Meio Ambiente e a Rede de Atenção Básica à Saúde" que foi desenvolvido entre os meses de abril e dezembro de 2017. Para o desenvolvimento do projeto foi selecionado o Bairro Maués do município de Vitória de Santo Antáo, Pernambuco, que apresentava vários problemas ambientais. Os riscos à saúde, decorrentes do meio ambiente, foram localizados e fotografados a partir das visitas ao território. Esses dados foram a base para o mapeamento ambiental do território, utilizando-se a ferramenta Google Earth. Foram identificados problemas ambientais, como esgotos sem saneamento, acúmulo de resíduos sólidos, terrenos baldios, matadouro clandestino e moradias inadequadas, apenas nas áreas periféricas do bairro. Os riscos estáo intimamente relacionados à ocorrência de diversas doenças infecciosas e parasitárias. A identificação clara desses problemas foi possível devido à utilização da ferramenta de mapeamento, demonstrando a importância dessa técnica na análise dos problemas ambientais e de saúde e na tomada de decisão, a fim de melhorar a qualidade de vida da população do território.

Palavras-chave: Mapeamento Geográfico. Meio Ambiente. Saúde Ambiental.

\section{ABSTRACT}

This text presents the experience report about the environmental mapping in health linked to the "Extension interface project between the environment and the network of basic health care" that was developed between the months of April and December of 2017. For the development of the project was selected the Maués Neighborhood in the city of Vitória de Santo Antão, State of Pernambuco, Brazil, which presented several environmental problems. The health risks, due to the environment, were located and photographed, through visits to the territory. These data were the basis for the environmental mapping of the territory, using the Google Earth tool. Environmental
Valdecir Barbosa da Silva Júnior

Graduando em Saúde Coletiva na Universidade Federal de Pernambuco, Brasil (junior-jlgg@hotmail.com).

Maria Tatiane Alves da Silva

Graduanda em Saúde Coletiva pela Universidade Federal de Pernambuco, Brasil (mtatianealves@hotmail.com).

Jorgiana de Oliveira Mangueira

Doutoranda em Saúde Coletiva pelo Centro de Pesquisas Aggeu Magalhães/ FIOCRUZ-Pernambuco, Brasil; professora no Curso de Saúde Coletiva da Universidade Federal de Pernambuco, Campus de Vitória de Santo Antão, Brasil (jorgianafisio@hotmail.com). 
problems were identified, such as sewerage without sanitation, solid waste accumulation, vacant lots, a clandestine slaughterhouse and inadequate housing, only in the outskirts of the neighborhood. The risks are closely related to the occurrence of various infectious and parasitic diseases. The clear identification of these problems was possible due to the use of the mapping tool, demonstrating the importance of this technique in the analysis of environmental and health problems and in decision making, in order to improve the quality of life of the population of the territory.

Keywords: Geographic Mapping. Environment. Environmental Health.

\section{INTRODUÇÃO}

O presente artigo aborda o relato de experiência sobre o mapeamento ambiental em saúde executado pelo projeto de extensão "Interface entre Meio Ambiente e a rede de Atenção Básica à Saúde”, que contou com a participaçáo de três docentes do curso de graduaçáo em Saúde Coletiva e um de Enfermagem do Centro Acadêmico de Vitória (CAV/UFPE - Universidade Federal de Pernambuco) e sete discentes, sendo cinco de Saúde Coletiva, um de Enfermagem e um de Ciências Biológicas. $\mathrm{O}$ projeto teve como um dos objetivos específicos mapear as áreas e fatores de riscos ambientais do município de Vitória de Santo Antão, Pernambuco.

Por muito tempo, a condição saudável do ser humano era interpretada como ausência de doença. Entretanto, a atual Constituição Federal Brasileira define saúde a partir de um conceito ampliado e como dever do Estado, garantido por meio de políticas públicas sociais e econômicas. Esse conceito incorpora os determinantes sociais como principal influência para o processo saúde-doença da populaçáo, com destaque para as condiçóes de vida e preservação ambiental (CARVALHO, 2013).

O modelo de produção industrial, iniciado no século XIX, promoveu grandes mudanças sociais e impulsionou o desenvolvimento das cidades. No entanto, a grande expansão da vida urbana não ocorreu de forma sistemática e organizada, o que acarretou graves problemas sociais e de infraestrutura. Dessa forma, a aglomeração intensa, 
ausência de saneamento básico e exploração inadequada do meio ambiente se caracterizam como um novo nicho de desenvolvimento de doenças (ARAÚJO, 2015).

Todo e qualquer território urbano, ao se desenvolver, passa por uma série de transformaçóes sociais, econômicas e ambientais. Essas transformaçóes caracterizam o ambiente urbano no decorrer do tempo e é dever do Estado coordenar tal processo, fato que não ocorre efetivamente. As cidades não apresentam problemas sociais uniformemente, devido à desigualdade social existente no país. Sendo assim, a população mais pobre é a que está em maior e frequente exposição a tais problemas e as doenças acarretadas por eles, criando um cenário desigual de adoecimento no território (SANTOS, 2011).

Apenas medidas de assistência à saúde são insuficientes para a proteção da saúde populacional, assim, são necessários meios que possibilitem prevenir o adoecimento. A identificação de riscos a saúde se caracteriza como um passo inicial para a prevenção, possibilitando a criação de planos de intervenção. Dessa forma, conhecer o território é fundamental para a identificação de riscos e o mapeamento destes amplia o potencial de intervenção (PEREHOUSKEI; ANGELIS FONZAR, 2015).

A análise espacial em saúde tem início historicamente com John Snow, considerado o pai da epidemiologia. O médico inglês mapeou os focos de ocorrência da cólera na Londres de 1854 e percebeu que o surto estava relacionado às fontes de água contaminadas. No mapa, é possível sinalizar problemas de saúde e ambientais, o que permite a integração dessas informações e possibilita análises que não poderiam ser realizadas sem ele. Essas características subsidiam a tomada de decisão em saúde (MACHADO; KATAR JÚNIOR; HARTOG, 2015; PEREHOUSKEI; ANGELIS; FONZAR, 2015).

\section{METODOLOGIA}

O projeto foi desenvolvido entre os meses de abril e dezembro de 2017. As atividades consistiram em visitas à Unidade de Saúde e seu território de cobertura; reunióes com a Equipe da Estratégia Saúde da Família (ESF) e com a Gestão Municipal da Saúde; treinamento 
para utilização da ferramenta Google Earth; e mapeamento de riscos ambientais à saúde do território.

\section{Área de Estudo}

O território selecionado para as atividades foi o Bairro Maués, no município de Vitória de Santo Antão-PE, que, segundo o Departamento de Atenção Básica do Município, apresentava uma população de aproximadamente 3.500 habitantes em 2018. O bairro é subdividido em nove microáreas, destas, foram trabalhadas três microáreas correspondentes aos territórios de cobertura dos Agentes Comunitários de Saúde (ACS) que se disponibilizaram a contribuir com o projeto de extensão.

Figura 1 - Localização geográfica do bairro Maués, Vitória de Santo Antão-PE

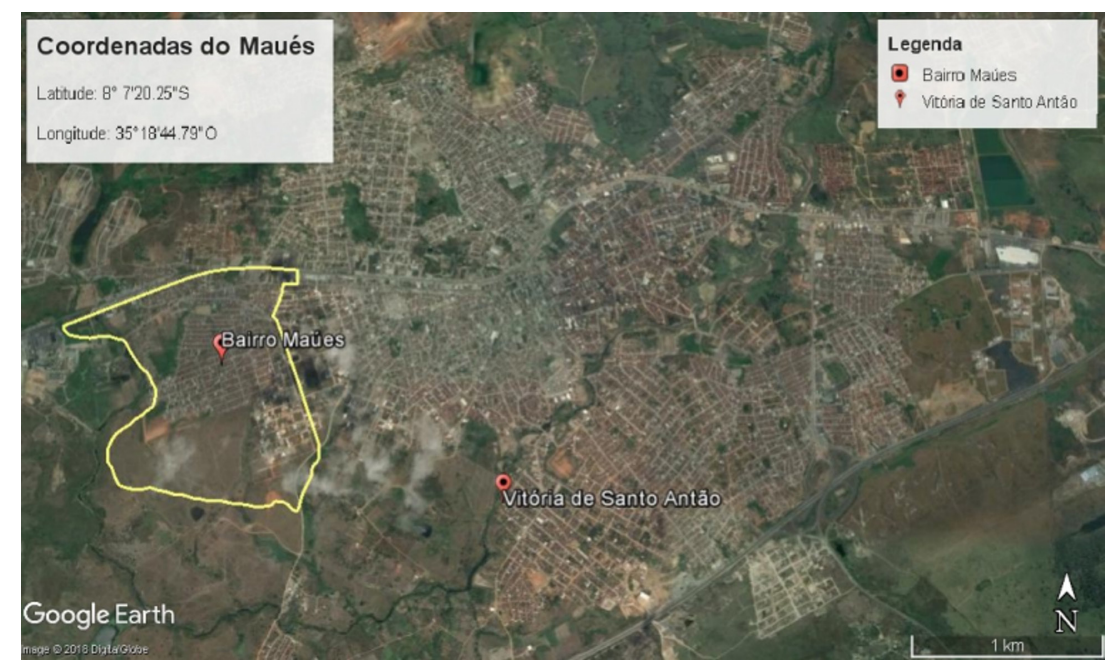

Fonte: Google Earth (2018).

\section{Procedimentos metodológicos}

A fim de identificar e localizar potenciais riscos ambientais, as visitas ao território foram realizadas com o apoio de três ACS e dois agentes de combate a endemias da equipe da ESF da Unidade de Saúde do 
bairro. As visitas ocorreram quinzenalmente com duração de duas horas e cada profissional da equipe apresentou a área de cobertura da ESF. Também foram realizadas visitas aos domicílios conjuntamente aos agentes de combate de endemias, totalizando cinco visitas.

O Google Earth é um software que permite a visualização da superfície da Terra por meio de imagens de satélite. Além disso, possibilita o delineamento e o mapeamento de áreas urbanas e rurais (MARTINS, 2013). Para que fosse possível a utilização da ferramenta pelos discentes do projeto de extensão, foi desenvolvido treinamento em formato de aula prática ministrada por um dos docentes do curso de Saúde Coletiva.

O mapeamento foi realizado nos primeiros quatro meses do projeto, e atualizado periodicamente. Os riscos ambientais foram fotografados e registrados os respectivos endereços. Posteriormente, esses endereços foram georreferenciados no mapa, na ferramenta Google Earth, e sinalizados com ícones para simbolizar os riscos. Os ícones sinalizadores foram: casa de catadores, ESF, esgoto, acúmulo de resíduos sólidos, matadouro, moradia inadequada e terreno baldio.

Após a finalização do mapeamento ambiental, os resultados foram apresentados, em reuniáo, pela equipe do projeto de extensão à equipe da ESF e discutidas possíveis ações de proteção e promoção à saúde, com enfoque nos riscos ambientais identificados. Seguidamente, os resultados do mapeamento e encaminhamentos da reuniáo foram apresentados e discutidos com a equipe gestora municipal de saúde, com o propósito de elencar possíveis propostas de enfrentamento à problemática. Tais propostas envolveram articulação com o Setor de Infraestrutura da Prefeitura Municipal, oficinas e açáo educativa com a população.

\section{Atividades desenvolvidas}

As oficinas educativas foram realizadas em grupo de idosos da comunidade com as seguintes temáticas abordadas: cuidados com resíduos sólidos, reciclagem, cuidados com os animais domésticos e animais para consumo humano e prevenção das arboviroses. Foram utilizados materiais educativos como panfletos sobre as temáticas e ilustraçôes. Cada oficina foi composta por uma dinâmica de integração, 
a partir do diálogo com os participantes durante a exposição do tema para que construíssem o conhecimento e um momento de avaliaçáo final do encontro. Além disso, foi realizada uma açáo educativa por meio de visitas domiciliares com entrega de panfletos informativos em toda a comunidade, abordando a problemática ambiental no território.

\section{RESULTADOS E DISCUSSÃO}

O Modelo da Determinação Social explica que as condiçôes de vida, como trabalho, distribuição de renda, saneamento e educação impactam no adoecimento populacional (CARVALHO, 2013). Dessa forma, o meio ambiente produz influência, tanto positiva, quanto negativa, na saúde dos indivíduos. Os riscos ambientais causados pelo modelo de produção e desenvolvimento social podem ocasionar sérios agravos à saúde, como doenças cardiovasculares, respiratórias e neoplasias. E no meio urbano com problemas de infraestrutura, como ausência de água tratada e instalaçóes sanitárias adequadas, acarretam a disseminação de doenças infecciosas e parasitárias (SOUZA, SANTOS, 2016).

A visita ao território com agentes de combate a endemias é apresentada na Figura 2. Essa visita foi realizada na parte central do bairro, onde é possível observar uma rua com calçamento, com ausência de acúmulo de resíduos sólidos. Entretanto, essa realidade não é observada em todo o bairro, pois foram identificados nas ruas mais periféricas riscos ambientais, os quais sinalizam a desigualdade social existente dentro deste território.

Durante as visitas domiciliares foram encontrados reservatórios de água inadequados, possibilitando ambientes propícios para a reprodução do mosquito transmissor da dengue. O vetor, Aedes aegypti, é exclusivamente urbano e a dengue é uma das principais doenças reemergentes, a qual mesmo com investimentos desde o final do século passado não foi possível o controle (ZARA et al., 2016). No entanto, a existência de reservatórios se torna necessária para essa população, devido aos longos períodos para o retorno de abastecimento de água potável, isso reflete o fato que o município de Vitória de Santo Antão-PE conta com uma cobertura de 63,3\% de esgotamento sanitário, e nem toda a população tem o acesso adequado 
ao abastecimento de água e saneamento básico (IBGE, 2018).

Figura 2 - Visita ao território com Agentes de Combate a Endemias, 2017.

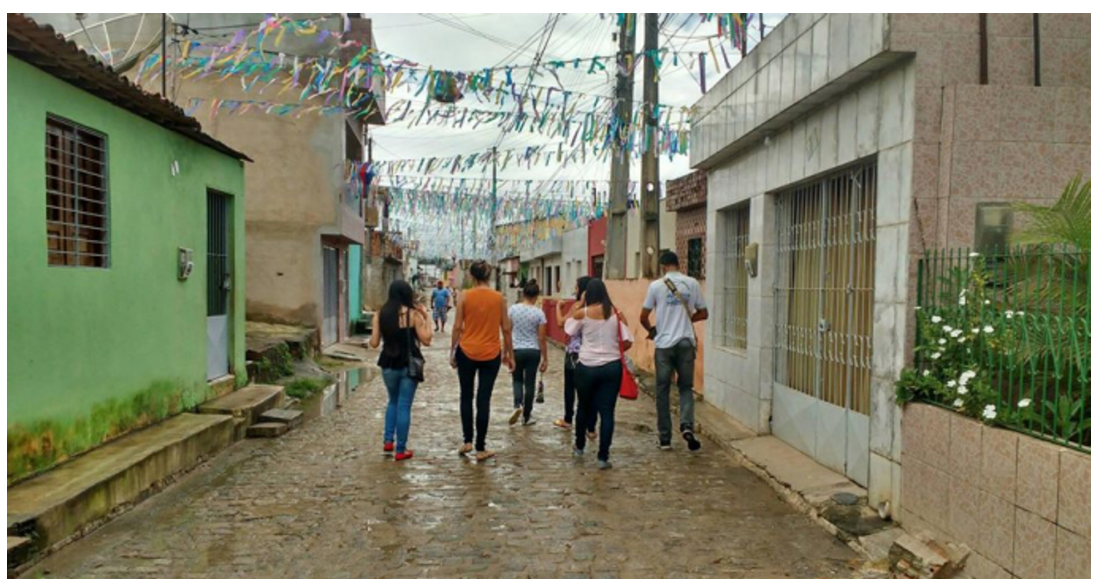

Fonte: Os autores (2017).

O córrego de esgoto com ausência de saneamento é apresentado na Figura 3, que demonstra a visita a uma parte periférica do bairro, sendo possível observar a presença de vários problemas ambientais, como moradia inadequada, esgoto não saneado e acúmulo de resíduos sólidos, ausência de calçamento na rua. Esses fatores trazem consigo precariedade à qualidade de vida da população dessa região do bairro e também estão associados à ocorrência de diversas doenças infecciosas e parasitárias, como, por exemplo, a leptospirose. Essa doença é transmitida principalmente por ratos e acomete predominantemente a população próxima a canais de esgotos sem saneamento (GONÇALVES et al., 2016). 
Figura 3: Córrego de esgoto com ausência de saneamento, 2017

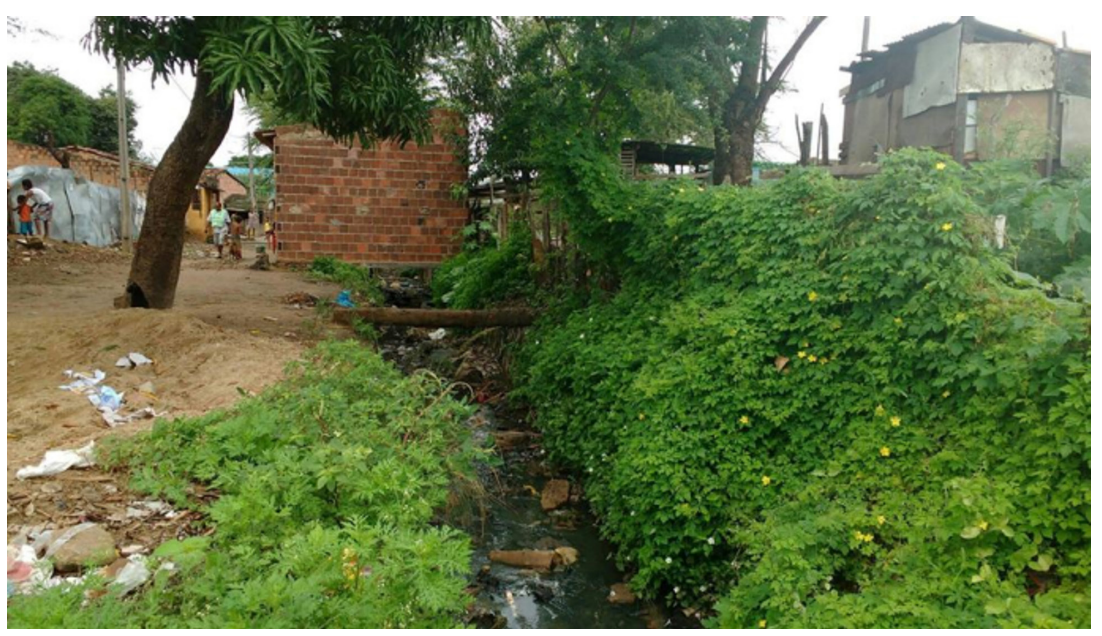

Fonte: Os autores (2017).

O mapeamento ambiental do bairro é apresentado na Figura 4. Foi observada e registrada, no mapa, a concentração de riscos ambientais nas ruas periféricas do bairro, como acúmulo de resíduos sólidos, terrenos baldios, esgoto não saneado, moradias inadequadas e matadouro clandestino. Dessa forma, a população residente nessas áreas apresenta maior vulnerabilidade ao desenvolvimento de diversas doenças infecciosas e parasitárias, uma vez que o contexto social, ambiental e econômico do território pode proporcionar um ambiente favorável para o surgimento dessas morbidades (BATALHA, 2014).

$\mathrm{Na}$ figura 4, foi registrada a presença de três moradias inadequadas construídas com restos de madeira. Além disso, foi encontrado um matadouro clandestino de bovinos e suínos, animais transmissores da Teníase, que é uma doença parasitária do intestino humano. Por ser clandestino, o lugar náo apresenta nenhuma forma de controle de qualidade, podendo acarretar no consumo de carnes contaminadas (FERREIRA, D., FERREIRA, F., 2017).

No território foram encontrados três terrenos baldios, seis esgotos não saneados e três acúmulos de resíduos sólidos. Atualmente, no Brasil, existe um modelo social de degradação do meio ambiente, influenciado pelo modelo de produção capitalista instalado no país a partir da década de 1970, que se preocupava prioritariamente com a 
política global de atração de investimentos em detrimento da questão ambiental (BRUGGER, 1994; SANTOS, 2011).

$\mathrm{Na}$ figura 4, também foram sinalizados equipamentos sociais pertinentes para o enfrentamento da problemática ambiental, como a Unidade de Saúde da ESF e duas casas de catadores.

Identificar pessoas que vivem da reciclagem de resíduos sólidos é uma informação importante para futuras estratégias, levando-se em consideração que não há, no município e no bairro, um trabalho de orientação quanto à coleta seletiva Essa problemática, mesmo sendo de responsabilidade do Estado, pode ser minimizada por açóes de preservação ambiental da populaçáo moradora, como, por exemplo, não jogar resíduos sólidos nas ruas e manter os reservatórios de água bem fechados (SOUZA; SANTOS, 2016).

Figura 4 - Mapeamento ambiental do bairro Maués, 2017.

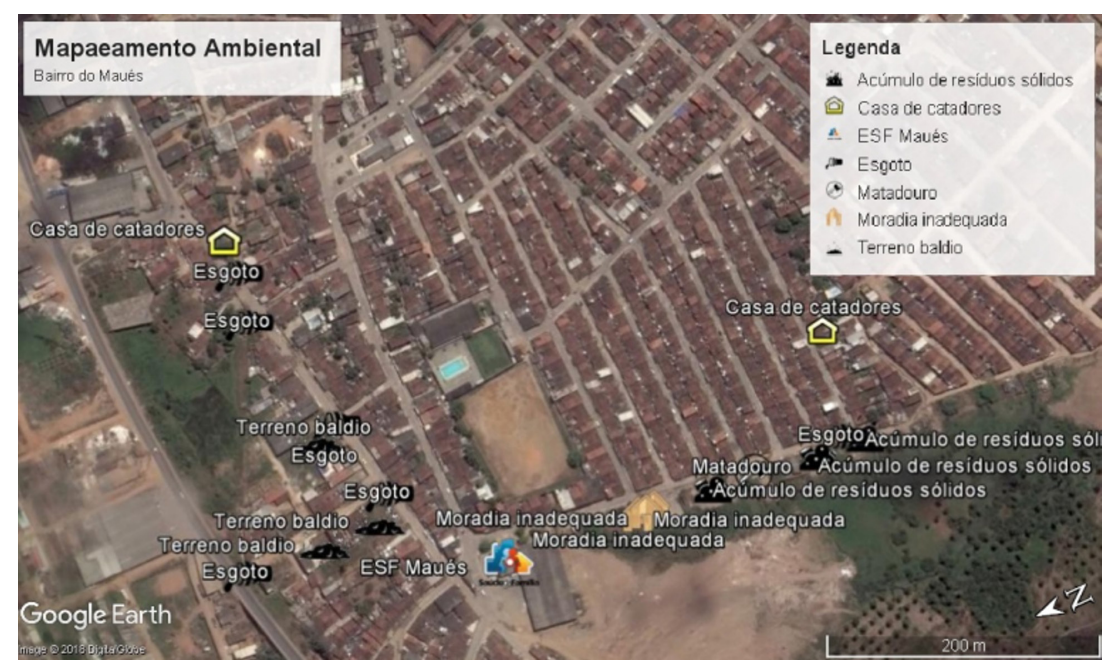

Fonte: Google Earth (2018).

A partir das reunióes com a equipe da ESF e equipe gestora da saúde surgiu, como encaminhamento, apresentar os resultados à Secretaria de Infraestrutura do município, pois, percebeu-se que a problemática ambiental precisava ser enfrentada intersetorialmente e não apenas pelo setor saúde (MONTEIRO, 2017).

Observou-se que as três oficinas foram um meio eficiente de discussão 
e abordagem dos temas sobre os riscos ambientais do território, partindo do conhecimento prévio que cada participante apresentava. E o diálogo com os participantes foi fundamental para a introdução dos temas. Ao final das oficinas, os idosos avaliavam o momento sempre de forma positiva e colaboraram sugerindo o tema "cuidado com animais peçonhentos", como escorpiōes, por ser comum no bairro, além de insetos.

No momento da ação educativa por meio de visitas domiciliares, a comunidade se mostrou aberta e sensível à discussão da temática dos riscos ambientais à saúde existentes no bairro. Os comunitários se mostraram inquietos com a situação do bairro e com a gestão municipal. Esse foi um relevante momento de reflexão sobre a problemática ambiental do bairro junto com os moradores da comunidade. Esse diálogo/processo educativo deve considerar que o meio ambiente tem elementos endógenos nos aspectos sociais, políticos e econômicos que podem produzir mudanças estruturais. É necessário levar em consideração a interação do homem com o meio ambiente. A educação ambiental não é um processo meramente técnico, seus resultados aparecem em longo prazo. Nesse sentido, ela é transformadora, propicia não apenas a compreensão na necessidade de preservação, mas também a qualidade socioambiental do mundo em que se vive (BRUGGER, 1994).

As ações extensionistas demonstraram a importância do eixo extensão como forma de compartilhar informaçóes adquiridas na Universidade e a importância do diálogo e da troca de informaçôes e saberes com a sociedade. Considera-se essa experiência como uma forma de integração do enfrentamento aos determinantes sociais da saúde entre a população e a Universidade.

\section{CONSIDERAÇÕES FINAIS}

A identificação dos problemas ambientais concentrados nas ruas periféricas do bairro foi um exercício importante para constatar a distribuição geográfica dos riscos. A ferramenta do Google Earth foi de fácil acesso e permitiu o registro cotidiano de informaçóes, dadas às alteraçóes que podem ocorrer no território. A visualização de áreas 
com riscos ambientais mais críticos permitiu o direcionamento de açóes educativas para grupos populacionais e domicílios específicos.

No entanto, os problemas ambientais estruturais e profundamente enraizados do Bairro Maués não são facilmente resolvidos, nem apenas as ações educativas pontuais são, por si só, suficientes para dar conta de tais questóes. Compreende-se que há uma ausência de políticas públicas para o enfrentamento dos problemas ambientais, uma atuação limitada do setor saúde que não dialoga com outros setores. Ficou evidente a importância de a Universidade promover, por meio de açóes contínuas de extensão, o diálogo com diferentes setores além do setor saúde. Os riscos ambientais que o território apresenta são de natureza complexa. Assim, existe a necessidade da integração de políticas públicas sociais que favoreçam a preservação ambiental.

\section{REFERÊNCIAS}

ARAÚJO, P. R. Evolução da mortalidade por doenças infecciosas e parasitárias. 2015. 60 f. Dissertação (Mestrado), Fundação Oswaldo Cruz, Teresina, 2015.

BATALHA, E. Geografia da saúde: contexto é dimensão essencial das políticas e açóes de saúde. RADIS, Rio de Janeiro, n. 138, p. 10-13, mar. 2014.

BRUGGER, P. Educação ou adestramento ambiental? Florianópolis: Letras Contemporâneas, 1994. 142 p.

CARVALHO, A. I. de. Determinantes sociais, econômicos e ambientais da saúde. In: Fundação Oswaldo Cruz (Org.). A saúde no Brasil em 2030 - prospecçáo estratégica do sistema de saúde brasileiro: populaçáo e perfil sanitário. Rio de Janeiro: Fiocruz; Ipea; MS, 2013. p. 19-38.

FERREIRA, D.; FERREIRA, F. L. A. Teniase e Cisticercose. PUBVET, Maringá, v.11, n.2, p.154-158, fev. 2017. Doi: 10.22256/ pubvet.v11n2.154-158.

GONÇALVES, N. V. et al. Distribuição espaço-temporal da leptospirose e fatores de risco em Belém, Pará, Brasil. Ciência \& Saúde Coletiva, Rio de Janeiro, v. 21, n. 12, p. 3.947-3.955, 2016. 
Doi: 10.1590/1413-812320152112.07022016.

IBGE - Instituto Brasileiro de Geografia e Estatística. Brasil, Pernambuco, Vitória de Santo Antáo. Disponível em: https:// cidades.ibge.gov.br/brasil/pe/vitoria-de-santo-antao/panorama. Acesso em: 28 out. 2018.

MARTINS, L. J.; SEABRA, V. da S.; CARVALHO, V. S. G. de. O uso do Google Earth como ferramenta no ensino básico da Geografia. SIMPÓSIO BRASILEIRO DE SENSORIAMENTO REMOTO, FOZ DO IGUAÇU, 16., 2013, Foz do Iguaçu. Anais [...], Foz do Iguaçu: IPEA, 2013.

MONTEIRO, M. R. Promoção da saúde: recurso hídrico, educação, saúde e meio ambiente para a prática da cidadania no interior do Amazonas. Revista SUSTINERE, Rio de Janeiro, v. 5, n. 1, p. 5-23, jan.-jun. 2017. Doi: 10.12957/sustinere.2017.27825.

RIBEIRO, N. A. S; TELLES, E. O.; BALIAN, S. de C. O complexo teníase humana-cisticercose: ainda um sério problema de saúde pública. MV\&Z, São Paulo, v. 10, n. 1, 2012.

SANTOS, M. O espaço da cidadania e outras reflexóes. Porto Alegre: Fundação Ulysses Guimarães, 2011. 205 p.

SANTOS, T. C. C.; CÂMARA, J. B. D. GEO Brasil 2002: perspectivas do meio ambiente no Brasil. Brasília: Ediçóes IBAMA, 2002. $440 \mathrm{p}$.

SOUZA, P. D. F. B.; SANTOS, D. B. Percepçáo de alunos sobre a relaçáo saúde e meio ambiente. Carpe Diem, Natal, v. 14, n. 1, 2016. Disponível em: https://periodicos.unifacex.com.br/revista/article/ view/697. Acesso em: 28 out. 2018.

ZARA, A. L. de S. A. et al. Estratégias de controle do Aedes aegypti: uma revisão. Epidemiol. Serv. Saúde, Brasília, v. 25, n. 2, p. 391-404, abr.-jun. 2016. Doi: 10.5123/s1679-49742016000200017.

Submetido em 2 de setembro de 2018.

Aprovado em 5 de novembro de 2018. 